\begin{tabular}{|c|c|}
\hline 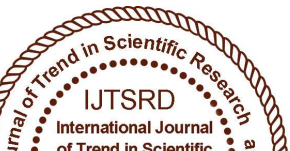 & $\begin{array}{l}\text { International Journal of Trend in Scientific } \\
\text { Research and Development (IJTSRD) }\end{array}$ \\
\hline $\begin{array}{lll} & \\
0\end{array}$ & International Open Access Journal \\
\hline and & ISSN No: $2456-6470$ | www.ijtsrd.com | Volume - 2 | Issue -3 \\
\hline
\end{tabular}

\title{
Tri-band Microstrip Patch Antenna for Satellite Communication
}

\author{
Abirami R \\ Student, Electronics and \\ Communication Engineering, \\ Jeppiaar Maamallan Engineering \\ College, Sriperumpudur, \\ Tamil Nadu, India
}

\author{
Jasmine Vijithra A \\ Assistant Professor, Electronics \\ and Communication Engineering, \\ Jeppiaar Maamallan Engineering \\ College, Sriperumpudur, \\ Tamil Nadu, India
}

\author{
Benisha M \\ Assistant Professor, Electronics \\ and Communication Engineering, \\ Jeppiaar Institute of Technology, \\ Sriperumpudur, \\ Tamil Nadu, India
}

\begin{abstract}
A compact and high gain micro strip patch antenna is proposed for satellite communication. The antenna covers the frequency of C-band, X-band and Ku-band. The proposed antenna having the maximum reflection coefficient of -28.076 at $13.13 \mathrm{GHz}$. This antenna achieves high gain and directivity. Four circular slots are inserted into the rectangular patch of the antenna. Low cost FR4 dielectric is used as a substrate material. The antenna provides the bandwidth of $14 \mathrm{GHz}$. The gain achieved by the antenna is $3.04 \mathrm{dBi}$ at $4 \mathrm{GHz}, 4.90 \mathrm{dBi}$ at $8 \mathrm{GHz}, 1.88 \mathrm{dBi}$ at $12 \mathrm{GHz}$ and $8.29 \mathrm{dBi}$ at $18 \mathrm{GHz}$. The design and simulation of the Microstrip antenna is done by Advanced Design System(ADS) software 2016 version.
\end{abstract}

\section{KEYWORDS: Microstrip, triband, ADS}

\section{INTRODUCTION}

Antenna is a very essential component in various wireless communications systems [1]. Nowadays Satellite technology is growing fast and the applications for satellite technology are increasing all the time. Micro strip patch antennas are becoming widely useful because of their characteristics of printed directly onto a circuit board, low cost, have a low profile and are easily fabricated. In Micro strip antenna complexity of design is very less. Wide band micro strip antenna can be used in the applications of Satellite Space craft, Air craft, Missile, Radar Communication. Antenna is an electronic device which is used for both transmission and reception.
Triband encapsulates X-band, C-band and Ku-band. A band is a small section of spectrum. As per the IEEE standards, the frequency covered by $\mathrm{C}$-band is $4-8$ $\mathrm{GHz}$. The frequency of $\mathrm{X}$-band is from $8.0-12.0$ $\mathrm{GHz}$ and the frequency of $\mathrm{Ku}$-band is from 12.0-18.0 GHz. Research shows that cutting slots in radiating patch and the operating frequency is shifted by a small ground plane and resonating frequencies are raised [2]. Antennae are the ones which have a very large bandwidth and hence they can be used for many applications [3][4].

During the last decade, the cost of the micro strip antenna has reduced, because of the advancement of its technology and increasing investment in this sector commercially [5]. Nowadays multi frequencies and multiband antennas are becoming very much popular because of their operation. Using single antenna different resonant frequencies are achieved.

\section{Designing formulas:}

Selecting the resonant frequency and a dielectric medium for designing of micro strip patch antenna.

\section{A. Width $(W)$ :}

The width of the patch is computed using the following equation, [6][7][8]

$$
\mathrm{W}=\frac{C_{0}}{2 f_{r}} \sqrt{\frac{2}{\varepsilon_{r}+1}}
$$

Where, 
$\mathrm{W}=$ Width of the patch

$C_{0}=$ Speed of light

$\varepsilon_{r}=$ Value of the dielectric substrate

\section{B.Effective refractive index:}

The radiating wave is travelling from the patch in the direction of ground plane pass through air and some pass through substrate. The amount of the effective dielectric constant $\left(\varepsilon_{\text {reff }}\right)$ is computed using the following equation [6][7][8]:

$$
\varepsilon_{\text {reff }}=\frac{\varepsilon_{r}+1}{2}+\frac{\varepsilon_{r}-1}{2}\left[1+12 \frac{h}{W}\right]^{-1 / 2}, W / h^{>1}
$$

\section{Length:}

Calculating the actual rise in length $(\Delta \mathrm{L})$ of the patch using the successive equation [6][7][8]

$$
\frac{\Delta L}{h}=0.412 \frac{\left(\epsilon_{\text {reff }}+0.3\right)\left(\frac{w}{h}+0.264\right)}{\left(\epsilon_{\text {reff }}-0.258\right)\left(\frac{w}{h}+0.8\right)}
$$

Fig.1 Design of triband antenna

Where ' $h$ '=height of the substrate

The length $(\mathrm{L})$ of the patch is instantly be computed using the below equation [6][7][8]

$$
\mathrm{L}=\frac{C_{0}}{2 f \sqrt{\varepsilon_{r e f f}}}-2 \Delta L
$$

\section{Result analysis and Calculation:}

The micro strip patch antenna was simulated and results were analyzed using ADS.

\section{A. Reflection Coefficient:}

The variation of reflection coefficient in accordance with frequency is illustrated in Fig.2. From Fig.2 the maximum reflection coefficient achieved is -28.076 $\mathrm{dB}$ at $13.13 \mathrm{GHz}$. The bandwidth of the antenna is 14 $\mathrm{GHz}$. The resonant frequency is $13.13 \mathrm{GHz}$.

$$
\begin{aligned}
& L_{g}=6 \mathrm{~h}+\mathrm{L} \\
& W_{g}=6 \mathrm{~h}+\mathrm{W}
\end{aligned}
$$

D. Length $(\mathrm{Lg})$ and Width (Wg) of Ground Plane:

The length and width of a substrate is same as the length and width of the ground plane.

\section{Antenna Design:}

Fig. 1 shows the design of micro strip patch antenna. FR4 substrate is used as a substrate which is having the relative permittivity $\varepsilon_{r}$ of 4.6 and the loss tangent of 0.01 . The substrate thickness is $1.6 \mathrm{~mm}$. The proposed antenna resonates at $4 \mathrm{GHz}$. $50 \mathrm{ohms}$ of input impedance is given through the port of the antenna. The rectangular patch which is having the four circular slots with the radius of $2 \mathrm{~mm}$. The length and width of the patch is $22.4 \mathrm{~mm}$ and $17.01 \mathrm{~mm}$ as in accordingly and the length and width of the substrate is $32 \mathrm{~mm}$ and $26.61 \mathrm{~mm}$ respectively.

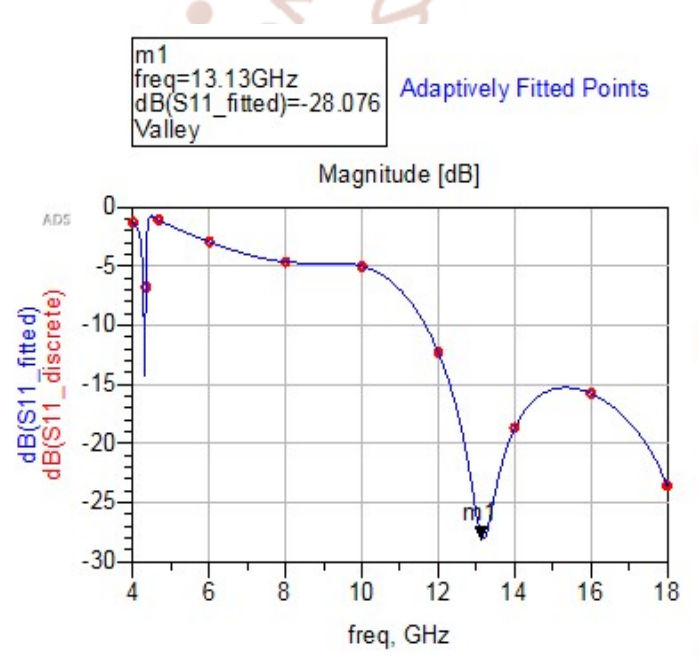

Fig.2 Reflection Coefficient of Proposed antenna

B. Gain and Directivity:

The simulated gain of proposed antenna with respect to frequency is revealed in Fig.3. Gain is varied from $0.86 \mathrm{dBi}$ to $8.29 \mathrm{dBi}$ at the frequency of $4 \mathrm{GHz}$ to 8 GHz. The gain is varied in accordance with frequency. 
International Journal of Trend in Scientific Research and Development (IJTSRD) ISSN: 2456-6470

Gain (dBi)

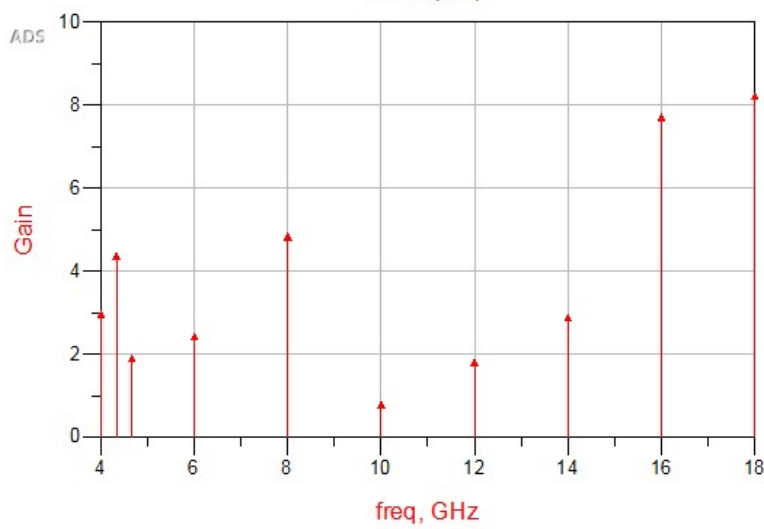

Fig.3 Simulated gain Vs frequency plot

Directivity is overall range of of how directional the radiation pattern is. The simulation directivity of antenna in accordance with frequency is depicted from Fig.4.
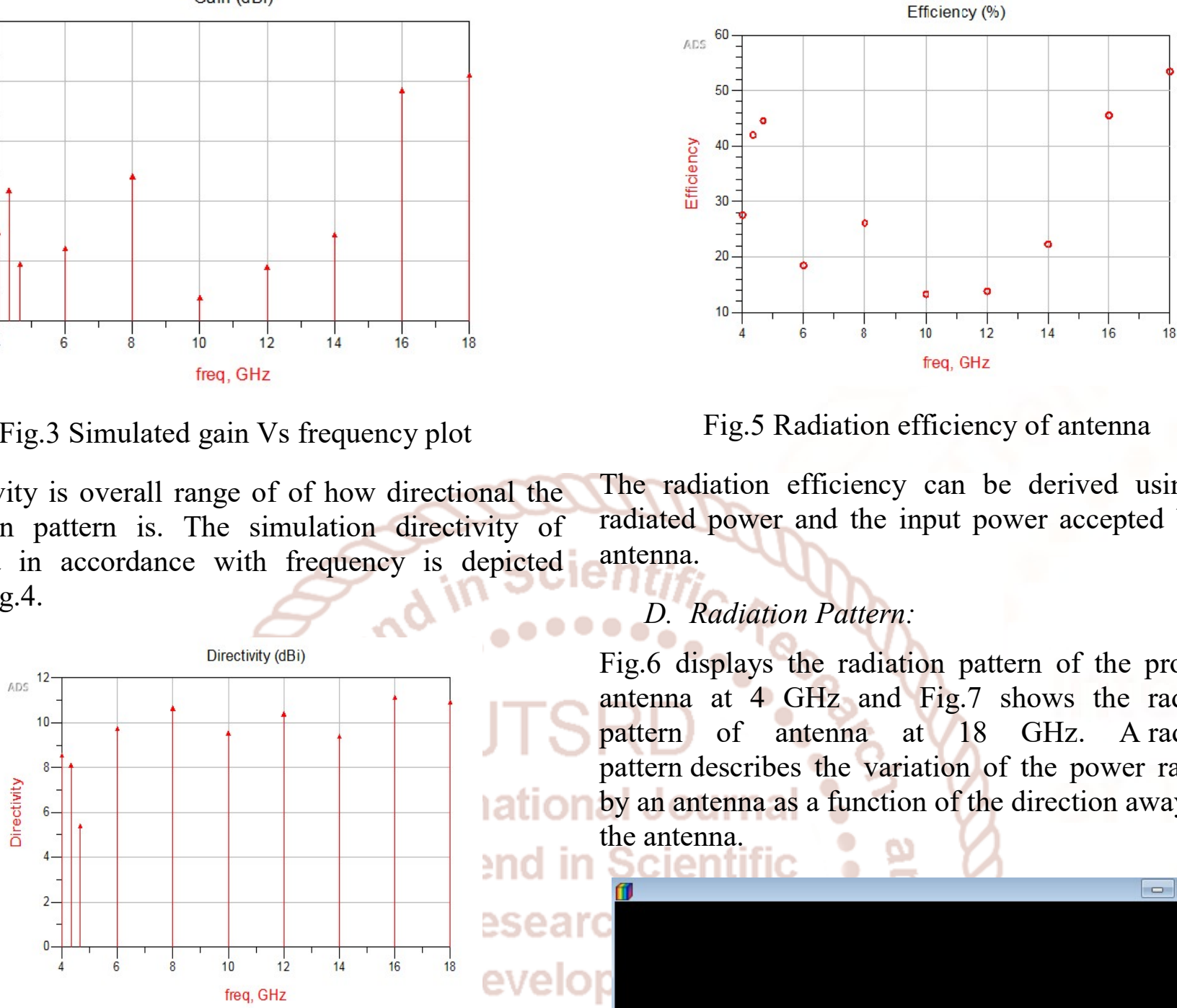

Fig.5 Radiation efficiency of antenna

The radiation efficiency can be derived using the radiated power and the input power accepted by the antenna.

\section{Radiation Pattern:}

Fig. 6 displays the radiation pattern of the proposed antenna at $4 \mathrm{GHz}$ and Fig.7 shows the radiation pattern of antenna at $18 \mathrm{GHz}$. A radiation pattern describes the variation of the power radiated by an antenna as a function of the direction away from the antenna.

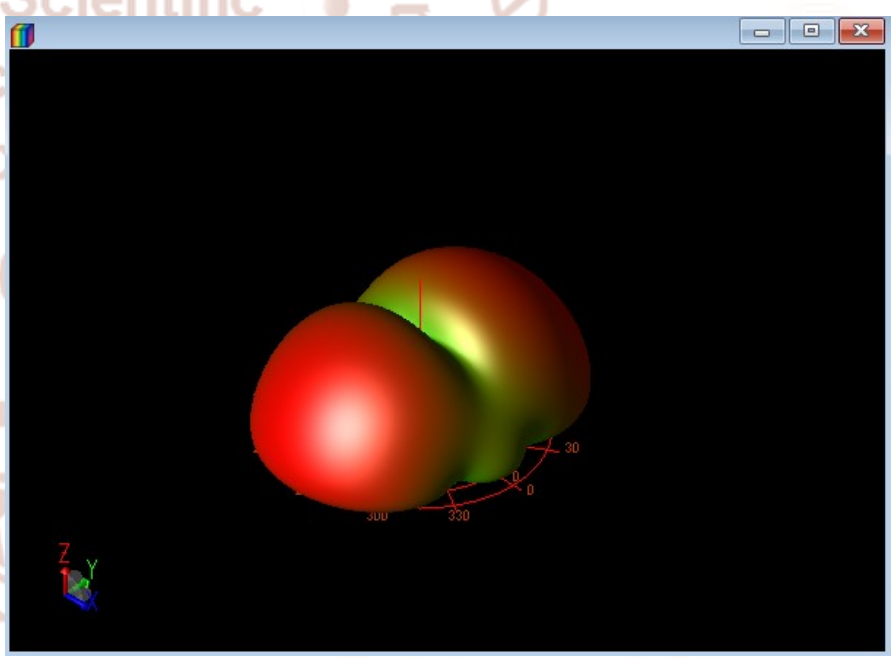

Fig.6 Radiation pattern of antenna at $4 \mathrm{GHz}$

The directivity and gain of the antenna for different frequencies are presented in Table.1.

\section{TABLE. 1 PARAMETERS OF PROPOSED ANTENNA}

\begin{tabular}{|l|l|l|}
\hline $\begin{array}{l}\text { Frequency } \\
(\mathrm{GHz})\end{array}$ & $\begin{array}{l}\text { Gain } \\
(\mathrm{dBi})\end{array}$ & $\begin{array}{l}\text { Directivity } \\
(\mathrm{dBi})\end{array}$ \\
\hline $\mathbf{4}$ & 3.04 & 8.63 \\
\hline $\mathbf{6}$ & 2.49 & 9.83 \\
\hline $\mathbf{8}$ & 4.90 & 10.74 \\
\hline $\mathbf{1 0}$ & 0.86 & 9.64 \\
\hline $\mathbf{1 2}$ & 1.88 & 10.48 \\
\hline $\mathbf{1 4}$ & 2.96 & 9.48 \\
\hline $\mathbf{1 6}$ & 7.79 & 11.20 \\
\hline $\mathbf{1 8}$ & 8.29 & 11.01 \\
\hline
\end{tabular}

\section{Radiation efficiency:}

Fig.5 shows the radiation efficiency of the designed antenna. 


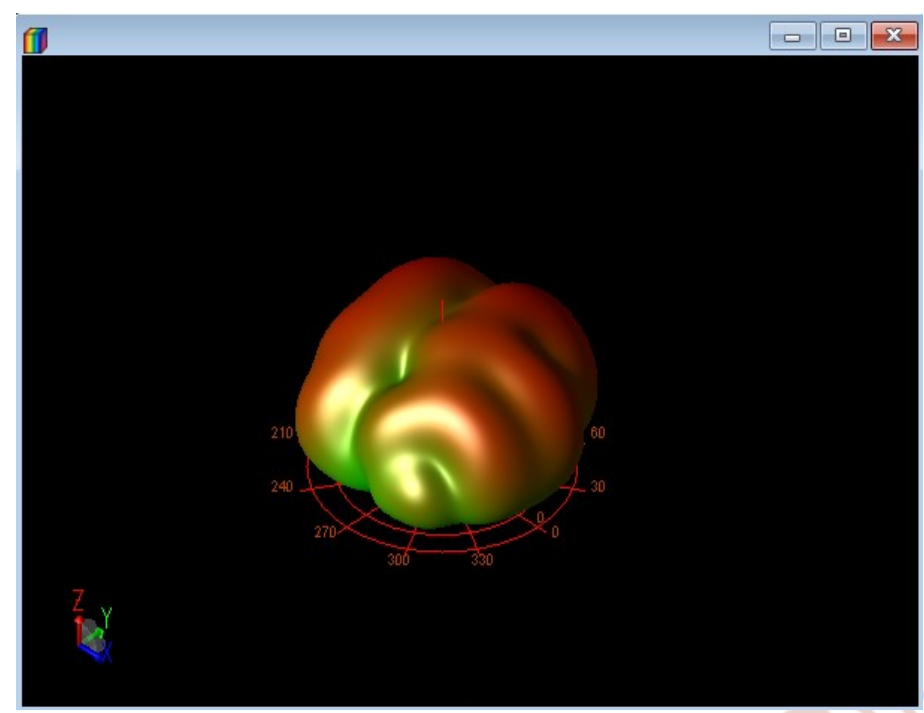

Fig.7 Radiation pattern of antenna at $18 \mathrm{GHz}$

\section{Conclusion:}

A simple design of microstrip patch antenna with slots is proposed in this paper. The designed antenna is radiated from $4 \mathrm{GHz}$ to $18 \mathrm{GHz}$ of triband frequencies. In this paper the antenna achieves high gain upto $8.29 \mathrm{dBi}$ and high directivity. The simulation result shows the antenna reaches high reflection coefficient of -28.076 . The performance of the antenna is improved.

\section{References:}

1) Jia Wei, Xing Jiang, Lin Peng, "Ultra Wideband and High Gain Circularly Polarized Antenna with Double-YShape Slot" IEEE Antennas and Wireless Propagation Letters (Volume: PP, Issue: 99) 2017.

2) M.H. Diallo Yaccoub, Achraf Jaoujal, "Rectangular Ring Micro strip Patch Antennas for Ultra-wide Band Applications",International journal of innovation and applied studies, vol. 4, pp. 441-446, 2 Oct 2013

3) Irina Vendik, Alexander Rusakov, Komsan Kanjanasit, Jason Hong, Dmitry Filonov, "UltraWideband (UWB) Planar Antenna with Single-, Dual-, and Triple-Band Notched Characteristic
Based on Electric Ring Resonator", IEEE Antennas and Wireless Propagation Letters 2017, Volume: PP, Issue: 99.

4) Ritika Bansal; Jagriti Bhatia; Amandeep Batth, "A novel lower ultra wideband (UWB) compact planar Inverted-F Antenna for WBAN applications", 5th International Conference on Reliability, Infocom Technologies and Optimization (Trends and Future Directions) (ICRITO) 2016, Pages: 464 - 467.

5) Prerna Gupta; S. N. Vijay, "Design and parametric study of rectangular micro -strip patch antenna for Band Satellite Communication", International Conference on Recent Advances and Innovations in Engineering (ICRAIE) 2016, Pages: 1 - 5.

6) Ramna, Amandeep Singh Sappal "Design of Rectangular Microstrip Patch Antenna using particle swarm optimization", International Journal of Advanced Research in Computer and Communication EngineeringVol. 2, Issue 7, July 2013.

7) J. G. Vera-Dimas, M. Tecpoyotl-Torres, P. Vargas-Chable, J. A. Damián-Morales J. Escobedo-Alatorre and S. Koshevaya "Individual Patch Antenna and Antenna Patch Array for Wi-Fi Communication" Center for Research of Engineering and Applied Sciences (CIICAp), Autonomous University of Morelos State (UAEM), 62209, Av. Universidad No.1001, Col Chamilpa, Cuernavaca, Morelos, México.

8) Md. MarufAhamed, Kishore Bhowmik, Abdulla Al Suman "Analysis And Design of Rectangular Microstrip Patch Antenna On Different Resonant Frequencies for Pervasive Wireless Communication" International Journal of Scientific \& Technology Research Volume 1, Issue 5, June 2012. 